\title{
The Financial Stability Of Sustainable Organisations
}

Peter Johnson, Institute for Sustainable Leadership and Macquarie Graduate School of Management, Australia

\begin{abstract}
Research by Avery and Bergsteiner (2010) has found that Honeybee organisations, those that practice the principles of Sustainable Leadership, tend to perform better financially than those purely focused on generating profit. Financial analysis applies the concept of risk to adjust returns for the risks the organisations were exposed to in order to achieve the returns. This study applied the idea of stability, being the opposite of volatility, to evaluate the financial performance of three pairs of comparable organisations that operate in different industry sectors where each pair consists of a sustainable and a non-sustainable organisation as defined by DJSI index membership in 2010. In order to obtain a complete picture a mixture of internal and external financial measures was considered. This preliminary study found that sustainable organisations are more financially stable and maintain a lower risk profile.
\end{abstract}

Keywords: Sustainability; Sustainable Leadership; Finance, Risk

\section{INTRODUCTION}

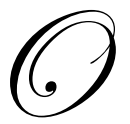

ver the last quarter century ${ }^{1}$, the concept of sustainability has received growing attention for a number of reasons, not least being Climate Change and the Global Financial Crisis (GFC). In 2005, a UN

World Summit defined the three broad pillars of sustainability to be: economic development; societal development; and, environmental protection (United Nations 2005). It follows that as societal participants, organisations $^{2}$ are increasingly implementing and executing organisational practices with the view to achieving societal and environmental outcomes in addition to the traditional economic outcomes. Balancing these three broad outcomes consistently and reliably requires thorough consideration of all decisions. This focus on achieving a balance of outcomes prevents sustainable organisations from becoming static entities which invariably would see them regressing, at least relatively, by motivating organisation leaders to constantly and incrementally evolve the organisation for the betterment of all stakeholders. Sustainable organisations should therefore also achieve greater consistency of performance, which in turn should lead to consistent value growth for all stakeholders, especially shareholders.

The GFC was arguably the worst economic downturn since the Great Depression. The general conclusion of government and organisation investigations has been poor risk management by those who should have known better, the large financial institutions and regulators (U.S. Government Accountability Office 2009). During the fifteen or so years prior (Elkington 2004) there had been a growing interest in the fields of corporate sustainability and corporate social responsibility (Dunphy, Griffiths et al. 2007). Whilst the downturn caused many organisations to change their focus from growth to survival, some were able to continue with minimal disruption whilst others saw an opportunity for growth. In general, these organisations had each been operating within its means and seeking long-term outcomes for both itself and the communities in which it operates (Avery and Bergsteiner 2010). This approach to business is possibly best summarised as:

\footnotetext{
${ }^{1}$ World Commission on Environment and Development published 'Our Common Future' in 1987.

2 Sometimes referred to a "corporate citizens".
} 
Pursuing a mission of sustainable development can make our firms more competitive, more resilient to shocks, nimbler in a fast-changing world, more unified in purpose, more likely to attract and hold customers and the best employees, and more at ease with regulators, banks, insurers, and financial markets (World Business Council for Sustainable Development 2001).

\section{ORGANISATIONAL SUSTAINABILITY}

The prevalent use of the term sustainability to mean "green" (environmental responsibility) in Australia has lead to the unfortunate situation whereby a very simple yet potentially powerful word has been usurped for only part of its meaning and thus only part of its value. A seemingly simple but considerably more powerful definition is intergenerational equity (Ott 2003). In 1987, the World Commission on Environment and Development clearly concerned with the propensity of some regions and or countries to live beyond their means defined Sustainable Development to mean development that meets the needs of the present without compromising the ability of future generations to meet their own needs (World Commission on Environment and Development 1987). The use of the world 'development' elicits a sense of phases of progress. Research (Dunphy, Griffiths et al. 2007) has found six phases of organisational commitment to sustainability: rejection, non-responsiveness, compliance, efficiency, strategic proactivity, and the sustaining organisation. The sustaining organisation has embedded the idea of sustainability into the organisation's culture thus made it systemic.

In the 2005 World Summit Outcome (United Nations 2005), Sustainable Development was defined to mean economic development, social development and environmental protection. Sustainability is therefore achieved and maintained by balancing these three outcomes. This definition of sustainability underpins the Triple Bottom Line reporting framework (Elkington 2004; Brown, Dillard et al. 2006). The Global Reporting Initiative (GRI) subsequently developed and extended this concept by developing a set of reporting guidelines for organisations (Global Reporting Initiative 2011). Whilst these reporting mechanisms are useful for framing discussions and ensuring a more holistic perspective of past and future outcomes, they provide little guidance on how they should be achieved. The realisation of these outcomes requires an effective system of principles, processes, practices and values (Avery and Bergsteiner 2010).

\section{Sustainable Leadership}

Avery and Bergsteiner (2010) take the view that effective leadership is about how [leaders and followers] interact with one another; their stakeholders; the organisation's systems, processes and culture; and the external environment. Sustainable Leadership is therefore the application of effective leadership to achieve the objectives of Sustainable Development, or put simply, the creation of enduring value for all stakeholders. Their research has found 20 management practices and 3 key performance drivers combine to produce the 5 major organisational outcomes: excellent brand and reputation; enhanced customer satisfaction; solid financial and operational performance; long-term shareholder value; and long-term stakeholder value.

Sustainable Leadership includes the responsibility for environment and social responsibility organisational practices as well as the financial performance organisational outcome comprising Sustainable Development. However, whilst many of the elements of Sustainable Leadership have been found to directly link to shareholder value creation it also includes the financial markets independence organisational practice. Investors have unique time horizons, return objectives and risk appetites therefore differing expectations of shareholder value creation. Additionally, due to the widespread use of funds management most people in Australia each indirectly own a share of the larger listed organisations through investment funds such as superannuation. As one large organisation taking market share from another results in an approximately net zero gain for many investors the short-term focus of financial markets is perhaps counter-productive to long-term value growth. Therefore, it is no longer in the best interests of many shareholders for organisations to follow the aggressively competitive style described as Locust by Avery and Bergsteiner (2010). 


\section{Organisational Resilience}

The Sustainable Leadership approach to organisations (Avery and Bergsteiner 2010) can be alternatively viewed from the perspective of minimising organisational shocks, internal and external. Organisations can absorb limited unexpected changes and challenges before the impacts become externally observable, for example, through financial reports and or the media. Unfortunately the patterns of behaviour that led to the issue are also likely to slow the response and compound the impact on organisational outcomes.

People issues such as under-performance and turnover can place a significant and undesirable strain on other resources to absorb the resulting issues and delays. Sustainable Leadership practices such as retaining staff and valuing staff can reduce or prevent these issues arising unnecessarily. Whilst developing people and succession planning will ensure that when a departure does occur there is a plan in place to minimise the disruption to internal and external deliverables. Taking a co-operative rather than competitive approach to labour relations can avoid or at least attenuate significant externally driven shocks such as strikes. Along with dependent stakeholders such as suppliers, external shocks can also result from independent stakeholders such environmental groups, local communities and the broader society in which the organisation operates. Therefore, considering stakeholders beyond shareholders and acting responsibly with regard to the environment and society can mitigate or avoid externally driven shocks. Acting responsibly however is more than simply meeting standards, although that is a good place to start, it is doing the right thing simply because it is the right thing to do, otherwise known as ethical behaviour. Similar to other leadership behaviours, acting ethically is a conscious behaviour that needs to be embraced, supported and demonstrated by the top to set the tone for the organisation.

Taking a long-term perspective will set a broader context and thus encourage behaviours and decisions that mitigate potential shocks whilst striving for and supporting the achievement of outcomes over a longer time horizon. This can often be observed through an organisation's approach to organisational change, those with a shorter perspective tend to attempt big change quickly, clearly a self-inflicted shock. Organisations taking a longer-term perspective will tend to change incrementally and continuously such that stability is accepted to be gradual improvement. This continuous change is guided by the organisation's vision which provides a view of the future desired by all and thus when accompanied by empowerment serves to engage all employees.

Unfortunately all of the above can do little to protect an organisation from externally driven financial and economic shocks, although arguably they will increase the organisation's ability to absorb them. During economic shocks many sustainable organisations will utilise retained profits to overtake competitors focused on survival. Financial shocks can occur simply due to perceptions held by financial analysts, or debt providers calling in debts to address their own shocks. Fortunately, organisations can avoid these shocks through self-funding or maximising their independence from others. The idea of using tangible assets such as retained profits to expand when others are contracting can also be applied to intangible assets. For example, being environmentally responsible may attract new customers when a competitor experiences an environmental shock. Therefore, sustainable practices not only reduce internal and external organisational shocks but may also support or enhance the organisation when other organisations experience shocks.

\section{RESEARCH QUESTION}

By adopting the practices of Sustainable Leadership an organisation is less likely to experience shocks and will be better able to respond to those that do occur. Therefore, it is expected that sustainable organisations will exhibit greater financial stability.

\section{METHODOLOGY}

There were two primary aspects to this study, the level of organisational sustainability and an analysis of financial stability. 


\section{Organisation Selection}

Ideally, a representative number of organisations would be individually assessed against the Sustainable Leadership practices however doing so for a reasonable number of organisations is a research study unto itself. Instead this study used an existing index as a proxy for mass evaluation. There are currently a number of organisations promoting differing evaluation methodologies, ranking reports and indices for organisation sustainability such as the Dow Jones Sustainability Indexes (DJSI) series of portfolio indices, the FTSE4Good indices, the Global Reporting Initiative (GRI) and the Carbon Disclosure Project (CDP), amongst others. However, participation in these initiatives is generally voluntary and in some cases also only by invitation. Of these four approaches the DJSI evaluate the most Sustainable Leadership practices and all of the outcomes (Dow Jones Sustainability Indexes), as such it was selected as the proxy for this study.

This study selected the most sustainable Australian organisation in three Global Industry Classification Standard (GICS) sectors as defined by 2010 DJSI rankings. The two Australian DJSI 'Supersector Leaders' were automatically selected (Dow Jones Sustainability Indexes 2010). Next, the Australian organisation with the highest weighting in the Asia-Pacific index and not in the same industry as either of the two previously selected organisations was selected as the third Australian organisation (Dow Jones Sustainability Indexes 2011).

Table 1 - Selected 'sustainable' organisations

\begin{tabular}{|l|l|l|l|}
\hline \multicolumn{2}{|c|}{ Organisation } & \multicolumn{1}{c|}{ Supersector } & \multicolumn{1}{c|}{ Selection Criteria } \\
\hline Australia \& New Zealand Banking Group & ANZ & Banks & Supersector Leader \\
\hline BHP Biliton & BHP & Basic Resources & $7.02 \%$ Asia-Pacific Index \\
\hline GPT Group & GPT & Real Estate & Supersector Leader \\
\hline
\end{tabular}

The selection process for the three less-sustainable organisations sought to ensure selection of appropriate and comparable organisations and was as follows:

1. Map DJSI 'supersectors' to ASX GICS industry codes.

2. Exclude from the appropriate S\&P/ASX 200 Industry indices those organisations listed in the DJSI AsiaPacific Index (Dow Jones Sustainability Indexes 2010).

3. Reduce list of organisations to those in the same or higher S\&P/ASX capitalisation index (Standard \& Poor's 2011).

4. If there are multiple organisations, randomly select one. This step was not required.

Table 2 - Selected 'less-sustainable' organisations

\begin{tabular}{|l|l|l|l|}
\hline \multicolumn{1}{|c|}{ Organisation } & \multicolumn{1}{c|}{ DJSI } & \multicolumn{1}{c|}{ ASX } \\
\hline Macquarie Group & MQG & Banks & Financials \\
\hline Newcrest Mining & NCM & Basic Resources & Materials \\
\hline Westfield Group & WDC & Real Estate & Property / REITs \\
\hline
\end{tabular}

\section{Financial Analysis}

The 'optimal' measure of financial performance depends largely on whether greater emphasis is put on growth or on risk. This study took the view that assuming growth exceeds inflation, risk is of primary importance followed by growth.

Risk is any uncertainty that affects a system in an unknown fashion and its ramifications are unknown, but it brings great fluctuation in value and outcome. Risk has a time horizon, meaning that uncertainty evolves over time, which affects measurable future outcomes and scenarios with respect to a benchmark (Mun 2006). 
There are three levels of uncertainty, the: known, unknown, and unknowable, where the unknown will become known through the passage of time, events and or action, however the unknowable, such as natural disasters, carry risk and uncertainty that may not change through the passage of time, events and or action. The greatest benefit of risk analysis is in the understanding, mitigating and or managing an organisation's unknown risks (Mun 2006). Whilst risk analysis informs regarding the value and structure of provisions it still requires organisational courage to maintain large provisions against market demands (Box 3-10, Avery and Bergsteiner 2010).

This study considered dividends, share prices and some internal financial ratios in comparing the selected pairs of organisations.

\section{Dividends}

Whilst financial markets use models such as the Dividend Discount Model (DDM) to determine the appropriate price of a share (Bodie, Kane et al. 2005), dividends are first and foremost a distribution of profit to shareholders. Sustainable organisations tend to have a predominance of buy-and-hold shareholders (Avery and Bergsteiner 2010) therefore this study considered dividends an investor income stream and analysed dividends for stability of growth using a mean-variance analysis of their changes.

\section{Share Price}

The occurrence of the Global Financial Crisis (GFC) during the analysis period provided the opportunity to examine the impact to the various organisations' financial stability during different economic and financial conditions. As such, the share price analysis was conducted for the four periods:

1. September 2004 - December 2010

2. $\quad$ Pre GFC 'Boom': September 2004 - September 2007 (36 months)

3. $\quad$ GFC 'Bust': October 2007 - March 2009 (18 months)

4. $\quad$ Post GFC 'Recovery': April 2009 - December 2010 (21 months)

An organisation's exposure to uncertainty and risks can be estimated by calculating the standard deviation of its resulting share price geometric returns (Mun 2006). Geometric returns give negative returns a greater influence on the averaging process with the resulting value being the constant rate of return required to match the actual performance (Bodie, Kane et al. 2005). Additionally, research by Samuelson (1970) found a significantly diminished importance of all moments beyond the mean and variance, and that both the mean and the variance have equal importance to investment outcomes. Accordingly, this study considered the mean and standard deviation of geometric returns of each organisation's share price.

Systemic risk is volatility explained by movements in variables external to an organisation such as the broader market. Unique risk relates to the movements that cannot be explained by external variables and must therefore relate to the organisation specifically. Diversification can thus only mitigate unique risks, as it is unable to change external and common variables. This study applied both the Capital Asset Pricing Model (CAPM) and Arbitrage Pricing Theory (APT) to expose and compare the stability of each organisation's underlying unique risk. In each case the S\&P/ASX 200 index was used as the proxy for the market as membership of that index was one of the selection criteria. Acknowledging evidence that a organisation's industry is also a major determinant of extramarket systemic risk (Farrell 1997) the application of APT applied the industry index from the organisation selection process as a secondary factor. However, to avoid duplication the market and industry indices were uncorrelated (Farrell 1997). To provide for a reasonable time on either side of the GFC and allow for price lags caused by factors such as thin-trading (Brealey, Myers et al. 2005), monthly data for the period September 2004 to December 2010 was used.

As investors seek to maximise return for risk this study also compared the risk-return performance of the organisations using the Treynor and M2 measures. The Treynor ratio provides the return per unit of systemic risk (Bodie, Kane et al. 2005). The M2 measure uses total volatility as a measure of risk and provides the differential 
return relative to a benchmark index (Modigliani and Modigliani 1997) by adjusting returns to include a proportion of the risk-free asset such that the adjusted return matches the risk of the benchmark index. By equating the risks the returns can be directly compared. The resulting values were calculated relative to the broader S\&P/ASX 200 index, which had the following monthly performance characteristics:

Table 3 - Monthly ASX 200 index performance

\begin{tabular}{|l|c|c|c|c|}
\hline \multicolumn{1}{|c|}{ ASX 200 } & Sep 04 - Dec 10 & Sep 04 - Sep 07 & Oct 07 - Mar 09 & Apr 09 - Dec 10 \\
\hline Return & $0.38 \%$ & $1.66 \%$ & $-3.37 \%$ & $1.34 \%$ \\
\hline Risk & $4.37 \%$ & $2.43 \%$ & $5.69 \%$ & $4.11 \%$ \\
\hline
\end{tabular}

As previous empirical testing of CAPM had found the intercept was not at the risk-free rate (Farrell 1997) this study followed the common practice of using a bank benchmark rate as the risk-free rate, namely the average Australian 90 day Bank Bill swap rate for the period (Reserve Bank of Australia 2011).

Table 4 - Average Australian 90 day Bank Bill Swap rates used

\begin{tabular}{|c|c|c|c|}
\hline $\mathbf{0 9 / 0 4 - 1 2 / 1 0}$ & $\mathbf{0 9 / 0 4 - 0 9 / 0 7}$ & $\mathbf{1 0 / 0 7 - 0 3 / 0 9}$ & $\mathbf{0 4 / 0 8 - 1 2 / 1 0}$ \\
\hline $0.45 \%$ & $0.48 \%$ & $0.52 \%$ & $0.34 \%$ \\
\hline
\end{tabular}

Internal Financials

Research (Farrell 1997; Brealey, Myers et al. 2005) has found external stability is driven by internal decisions, practices and systems, therefore analysis of internal financials serves to validate of share price risk analysis results. An organisation's method of financing influences the risk exposure for its investors such that the more an organisation utilises debt the riskier its ordinary shares become. Whilst financial leverage does not change the risk or return on an organisations assets it does increase the risk premium required by shareholders. Additionally, as leverage multiplies the effect of equity returns ( $r$ ), during both good and bad times, it increases the organisation's systemic $(\beta)$ and unique risks by becoming more volatile (Brealey, Myers et al. 2005). The following equation demonstrates this relationship where $\mathrm{L}$ refers to the leveraged version of an organisation and $\mathrm{U}$ to the unleveraged version (Farrell 1997):

$$
\beta_{L}=\left(1+\frac{D_{L}}{E_{L}}\right) \beta_{U}
$$

Further consideration of the addition of debt from an investor's perspective reveals that an investor's required return and beta for equity becomes

$$
\begin{aligned}
& r_{\text {equity }}=\left(\frac{\text { Assets }}{\text { Equity }}\right) r_{\text {assets }}-\left(\frac{\text { Debt }}{\text { Equity }}\right) r_{\text {debt }} \\
& \beta_{\text {equity }}=\left(\frac{\text { Assets }}{\text { Equity }}\right) \beta_{\text {assets }}-\left(\frac{\text { Debt }}{\text { Equity }}\right) \beta_{\text {debt }}
\end{aligned}
$$

This study compared the leverage (Asset / Equity) and gearing (Debt / Equity) ratios with the view that lower ratios are conducive to greater stability. However, this study assumed that taxes have no impact and therefore no evaluation was conducted regarding the optimality of debt levels through the availability of tax shields (Modigliani and Miller 1963; Miller 1977; DeAngelo and Masulis 1980; Howard and Brown 1992).

In addition to the leverage and gearing this study also considered each organisations Quick Ratio, Net Interest Cover and Net Profit After Tax (NPAT) results. The Quick Ratio was selected over the Current Ratio because some assets convert to cash faster than others, and inventories when sold quickly don't necessarily achieve their book value. Banks operate an intermediary service whereby they borrow from some and lend to others therefore they need to be evaluated slightly differently. The Net Interest Margin considers the borrow-lend margin 
on their interest earning assets. Increasing this margin is perceivably more constrained than profit margins of goods and services in other industries. A mean-variance analysis was used to identify how stably each organisation is maintaining or improving its internal financial results.

\section{ASSUMPTIONS AND CONSTRAINTS}

The primary assumptions underpinning this study were:

1. Dow Jones Sustainability Indexes' Asia Pacific Index is a reasonable proxy for evaluating current and historical organisation sustainability.

2. Efficient Market Hypothesis - semi-strong form and given the large capitalisation of each organisation the use of monthly price data allows for lag.

3. Splits, consolidations, rights issues and buy-backs were conducted at market value therefore had no impact on value of other shareholders.

4. GFC timeframe is the period of decline from October 2007 to March 2009.

5. Special dividends not included.

6. Franking of dividends has no impact on company or shareholder.

7. Based on empirical research (Treynor 1972; Holthausen 1981) this study has assumed the impact of any 'creative accounting' by an organisation to be trivial.

8. Taxes and transaction costs have no impact on organisation or shareholder.

9. Data sourced is true and accurate .

10. The 90 day Bank Bill Swap rate is a reasonable estimation for the risk-free rate in Australia.

11. Annual results duplicate interim therefore need to subtract interim values to expose bi-annual results.

12. A pattern in the selected measures is indicative of the organisation as a whole.

The primary constraint to this study was data availability, namely:

1. Westfield Group data available from August 2004.

2. $\quad$ ASX GICS index data available from July 2001.

3. ASX 200 index data available from March 2000.

\section{FINDINGS}

The three pairs of organisations each presented different scenarios yet arrived at a similar finding.

Table 5 - Summary of non-share price analysis results

\begin{tabular}{|l|c|c|c|}
\hline \multicolumn{1}{|c|}{ Industry } & Internal Financials & Financing & Dividends \\
\hline Financial & ANZ & - & ANZ \\
\hline Mining & BHP & NCM & BHP \\
\hline Real Estate & WDC & GPT & WDC \\
\hline
\end{tabular}

The operational stability of ANZ appears to provide financial stability through to the investor in the form of stable income (dividend) and capital (share price) returns, thus reducing the uncertainty and risk over the long term. These results are very much in-keeping with the idea of Sustainable Leadership where by solid financial performance and the creation long-term shareholder value appear to be being achieved with a lower risk profile than the approach being followed by MQG. Therefore, ANZ presented the clearest demonstration of the hypothesis that sustainable organisations are more financially stable.

The restructuring of financing at NCM appears to have had such a beneficial impact on its financial stability and performance in that it not only survived the GFC period but emerged from it as a seemingly stronger, more stable and more sustainable organisation. Whilst it was previously under-performing the industry, and even the market for a while, post-GFC it is performing relatively on-par with the industry and with considerably greater stability. In contrast, BHP was a solid performer in almost all measures. Of all six organisations, BHP was the best 
example of consistent and reliable dividends, even through the GFC period. However, the improvements at NCM have resulted in it operating with considerably lower leverage and gearing ratios that BHP in recent year.

The internal financials at both GPT and WDC were highly volatile during the analysis period however the NPAT results for WDC were far superior to that of GPT, albeit with more volatility. However, from a financing perspective GPT has been operating with a lower leverage and gearing than WDC. Both organisations had maintained a relatively stable dividend, until the GFC forced asset revaluations resulting in both organisations significantly reducing the dividend payment. This impacted GPT earlier and more severely thus WDC demonstrated greater resilience to unexpected shocks, possibly through a more conservative approach to asset acquisition and valuation that resulted in smaller changes necessary during the GFC.

Table 6 - Summary of share price analysis results

\begin{tabular}{|l|c|c|c|c|c|c|}
\hline & \multicolumn{3}{|c|}{ Share Price } & \multicolumn{3}{c|}{ Risk-Adjusted Performance } \\
\hline Industry & Pre-GFC & GFC & Post-GFC & Pre-GFC & GFC & Post-GFC \\
\hline Financial & ANZ & ANZ & ANZ & MQG & MQG & ANZ \\
\hline Mining & BHP & BHP & BHP & BHP & NCM & BHP \\
\hline Real Estate & WDC & WDC & WDC & GPT & GPT & GPT \\
\hline
\end{tabular}

Interestingly, ANZ's stable financial management and share price had not been well rewarded until the post-GFC period, when it achieved a risk-adjusted return better than MQG. The stability of BHP has been reflected in both a more stable share price and a superior risk-adjusted return, except for during the GFC when NCM outperformed most of the market. Whilst WDC achieved a more stable share price in all periods GPT achieved a superior, albeit only marginally, risk-adjusted return.

Given the organisation selection process followed the only surprising results came from WDC because whilst GPT achieved better debt management and risk-adjusted performance results, WDC achieved greater financial stability across the board such that WDC has arguably been the more sustainable organisation during the period. Unsurprisingly, further investigation uncovered that WDC is a member of the FTSE4Good Australia 30 index, along with $\mathrm{GPT}^{3}$.

FTSE4Good is an index series produced by FTSE and in comparison to DJSI concentrates on the social and environmental pillars of sustainability (FTSE4Good 2010). As can be seen below the FTSE4Good Australia 30 index weightings for the organisations analysed in this study are aligned with this study's results:

Table 7 - FTSE4Good weightings of organisations in this study

\begin{tabular}{|c|c|c|c|c|c|}
\hline ANZ & BHP & GPT & MQG & NCM & WDC \\
\hline $10.37 \%$ & $11.55 \%$ & $1.44 \%$ & $0 \%$ & $0 \%$ & $5.59 \%$ \\
\hline
\end{tabular}

\section{DISCUSSION}

The findings of this study could have been strengthened further had the analysis excluded members of any sustainability index or reporting mechanism rather than just those of the DJSI. This would have excluded WDC as a "less-sustainable" organisation and would have avoided the implicit and unintended comparison of sustainability indices.

Another key limitation was that the level of internal diversification, that is, a company's products and services, was excluded from the scope of the analysis as it was considered to be part of good management. However, some known external factors may have bolstered the results of some organisations, for example, the benefit of rising gold prices to NCM.

\footnotetext{
${ }^{3}$ Based on the results of this study it is assumed that ADC's absence from the DJSI Asia-Pacific index is due to it declining assessment rather than a poor assessment.
} 
Lastly, this study has made no attempt to account for organisational changes over time. For example, whilst ANZ has been the DJSI 'supersector' leader since 2007, before this time another Australian bank, Westpac Banking Corporation, held that position. Also, prior to 2008 DJSI did not evaluate the real estate sector and GPT only became the leader in 2009. The inclusion of such a temporal dimension to the analysis would have undoubtedly produced an even more robust outcome.

A worthwhile follow-up study would be to evaluate the financial stability of each organisation of the S\&P/ASX 200 and produce a ranking. The assertion being that each member of the DJSI Asia-Pacific index and or FTSE4Good Australia 30 index would appear in the top half of the ranking list.

\section{CONCLUSIONS}

This study sought to test quantitatively what qualitative literature suggests, namely that sustainable organisations are more financially stable than less-sustainable organisations. To this end this study has demonstrated that there is a quantitative basis for the assertion that sustainable organisations deliver a more stable performance in terms of shareholder value creation, in addition to delivering societal development and ecological protection. This results from the sustainable organisation's system of principles, processes, practices and values increasing its resilience to both internal and external shocks. This study has also demonstrated that stability of economic development is more systemic in sustainable organisations. Therefore, balancing outcomes of economic development, societal development and ecological protection makes good long-term commercial sense. Additionally, by virtue of the alignment between the practices and outcomes of Sustainable Leadership and the evaluation criteria used by DJSI, these results provide further evidence that the practices of Sustainable Leadership provide reasonable guidance for how organisations can achieve sustainability.

Conceptually, the findings of this study can be generalised to that of a whipsaw whereby small fluctuations in operations will amplify through the bottom line to create greater volatility of dividend payments and share price. Attempts to smooth the fluctuations at the shareholder stage will be more onerous and less reliable than employing sustainable practices to attenuate fluctuations and or, mitigate or avoid shocks systemically.

Although not explicitly intending to do so, this study has highlighted the discrepancies caused by variable and voluntary sustainability assessment. Therefore, the 'global leader' or other designation by any current 'independent' assessor cannot be taken on face value and certainly does not translate to having little room for improvement.

The conclusion of this preliminary study, within its constraints and assumptions, is that organisations achieving financial stability do so in all areas, from operations through to the bottom line and on to shareholders through dividend income and capital growth of share value. Therefore, organisational leaders are advised to focus on achieving stability of operations by adopting and embedding the principles and practices of Sustainable Leadership in order to deliver reasonable and reliable returns to stakeholders, especially shareholders over the long-term.

\section{AUTHOR INFORMATION}

Peter Johnson holds a Bachelor of Technology in Information and Communication Systems, and a Master of Commerce in Finance both from Macquarie University, and an MBA from the Macquarie Graduate School of Management. E-mail: peter@thejohnsons.com.au

\section{REFERENCES}

1. $\quad$ Avery, G. C. and H. Bergsteiner (2010). Honeybees \& Locusts, Allen \& Unwin.

2. Bodie, Z., A. Kane, et al. (2005). Investments, McGraw-Hill.

3. $\quad$ Brealey, R., S. Myers, et al. (2005). Principles of Corporate Finance, McGraw-Hill.

4. $\quad$ Brown, D., J. Dillard, et al. (2006). "Triple Bottom Line: A Business Metaphor for a Social Construct."

Retrieved 01 April 2011, from http://www.recercat.net/bitstream/2072/2223/1/UABDT06-2.pdf. 
5. $\quad$ DeAngelo, H. and R. Masulis (1980). "Optimal Capital Structure Under Corporate and Personal Taxation." Journal of Financial Economics 8: 5-29.

6. Dow Jones Sustainability Indexes. "Corporate Sustainability." Retrieved 20 March 2011, from http://www.sustainability-index.com/07_htmle/sustainability/corpsustainability.html.

7. Dow Jones Sustainability Indexes (2010). Dow Jones Sustainability Asia Pacific Index - Overview (by Country).

8. $\quad$ Dow Jones Sustainability Indexes (2010). "Global Supersector Leaders." Retrieved 28 Jan 2011, 2011, from http://www.sustainability-index.com/07_htmle/indexes/djsiworld_supersectorleaders_10_1.html.

9. Dow Jones Sustainability Indexes (2011). Dow Jones Sustainability Asia-Pacific Index Fact Sheet.

10. Dunphy, D., A. Griffiths, et al. (2007). Organizational Change for Corporate Sustainability, Routledge.

11. Elkington, J. (2004). Enter the Triple Bottom Line. The Triple Bottom Line: does it all add up?, Earthscan Books.

12. Farrell, J. L., Jr. (1997). Portfolio Management: Theory and Application, Irwin/McGraw-Hill.

13. FTSE4Good (2010). "FTSE4Good Inclusion Criteria." Retrieved 21 March 2011, from http://www.ftse.com/Indices/FTSE4Good_Index_Series/Downloads/F4G_Criteria.pdf.

14. Global Reporting Initiative (2011). "G3.1 Guidelines including Technical Protocol." Retrieved 24 March 2011, from http://www.globalreporting.org/NR/rdonlyres/660631D6-2A39-4850-9C0457436E4768BD/0/G31GuidelinesinclTechnicalProtocolFinal.pdf.

15. Holthausen, R. W. (1981). "Evidence on the Effect on Board Covenants and Management Compensation Contract on the Choice of Accounting Techniques: The Case for Depreciation Switch-Back." Journal of Accounting and Economics (3): 73-109.

16. Howard, P. F. and R. L. Brown (1992). "Dividend Policy and Capital Structure Under the Imputation Tax System: Some Clarifying Comments." Accounting and Finance 32(1): 51-61.

17. $\quad$ Miller, M. H. (1977). "Debt and Taxes." Journal of Finance 32: 261-276.

18. Modigliani, F. and M. H. Miller (1963). "Corporate Income Taxes and the Cost of Capital: A Correction." American Economic Review 53: 433-443.

19. Modigliani, F. and L. Modigliani (1997). "Risk-Adjusted Performance." Journal of Portfolio Management (Winter): 10.

20. Mun, J. (2006). Modeling Risk, Wiley.

21. Ott, K. (2003). "The Case for Strong Sustainability." Retrieved 01 April 2011, from http://umwethik.botanik.uni-greifswald.de/booklet/8_strong_sustainability.pdf.

22. Reserve Bank of Australia (2011). "Interest Rates and Yields - Money Market - Monthly." Retrieved 23 Feb 2011, from http://www.rba.gov.au/statistics/tables/xls/f01hist.xls?accessed=2302-09:29:03.

23. Samuelson, P. A. (1970). "The Fundamental Approximation Theorem of Portfolio Analysis in Terms of Means, Variances and Higher Moments." Review of Economic Studies 37.

24. $\quad$ Standard \& Poor's (2011). "Index Resources." Retrieved 28 Jan 2011, 2011, from http://www.standardandpoors.com/indices/main/en/us/.

25. Treynor, J. L. (1972). "Discussion of changes in accounting techniques and stock prices." Journal of Accounting Research (Empirical Research in Accounting: Selected Studies): 42-44.

26. U.S. Government Accountability Office (2009). "Financial Regulation: Review of Regulators' Oversight of Risk Management Systems at a Limited Number of Large, Complex Financial Institutions." Retrieved 01 April 2011, from http://www.gao.gov/products/GAO-09-499T.

27. United Nations (2005). "2005 World Summit Outcome." Retrieved 01 April 2011, from http://data.unaids.org/Topics/UniversalAccess/worldsummitoutcome_resolution_24oct2005_en.pdf.

28. World Business Council for Sustainable Development (2001). The Business Case for Sustainable Development: Making a difference toward the Johannesburg Summit 2002 and beyond.

29. World Commission on Environment and Development (1987). Our Common Future. 